\title{
Non-Sterile Dosing Disk Powder Filling Method
}

National Cancer Institute

\section{Source}

National Cancer Institute. Non-Sterile Dosing Disk Powder Filling Method. NCI

Thesaurus. Code C112992.

A process that fills a dosage unit using a dosing disk to deliver the powder, which is not performed under sterile conditions. 